\title{
MORTUARY PRACTICES AND THE NEGOTIATION OF SOCIAL IDENTITIES AT LM II KNOSSOS
}

\author{
IXTRODLCTON 1
}

THIs article explores new perspectives on the social dynamics at work at LM II Knossos, through a study of the manipulation of mortuary symbolism. In the past, the burial data have often been used to support an interpretation of mainland dominance or influence at Knossos. This is because, although different explanations have been advanced to account for the LM I B destructions in Crete, including invasion plus political takeover by mainlanders, and internal warfare, ${ }^{2}$ the subsequent innovations in material culture at Knossos are widely considered to be heavily indebted to contemporary mainland practices. Furthermore, on the basis of the Linear $\mathrm{B}$ and burial evidence particularly, this mainland influence has been equated with physical presence- if not actually as the cause of the LM I B disturbances, then in the aftermath. ${ }^{3}$

It is not the purpose of the present article to set forward arguments to support or refute the mainland invasion hypothesis. Rather, the concern is with the way that the burial record has been used in this debate. I shall argue that the theoretical premises underlying the interpretation of burial evidence here need re-evaluation, and that the arguments employed have involved an over-selective use of the data available. The first part of the article will outline some of the arguments based on the mortuary data that have contributed to the debate over mainland presence at LM II Knossos, and will consider the assumptions underlying these approaches. A more flexible thcoretical framework for the appreciation of the role of mortuary practices in past societies will be proposed, and the data from Knossos examined to provide empirical support for this framework. Through these LM II data, the potential of the burial context as an ideological arena will be proposed, a consideration which would be particularly relevant to our understanding of the social interactions underway in what was surely a very turbulent phase in Knossos' history.

\section{Previols APPROACHES TO GLLTLRAL IDENTITY IN THE}

\section{LM II BLRIAL RECORD}

Previous discussions of the mortuary innovations at Knossos have tended to bracket LM II and LMIII A tombs together, but in this article a stricter differentiation between the two ceramic

\footnotetext{
I should like to thank Cyprian Broodbank. Todd Whitelaw, and Oliver Dickinson for useful comments on drafts of this paper. Thanks go also to Sofia loutsaki for help and advice on this subject. I am also grateful to Marina Gkiasta for help in composing the Greck abstract. The doctoral research from which this article derives is funded by the British Academ:

: See P. Rehak and P. Younger. Revien of Aegean prehistory VII: Neopalatial. Final Palatial, and Postpalatial Crete. Af.t 102 (1998), 1.8. Also J. Driessen and C. Macdonald. The Troubled Istand: Minoan Crete before and after the Santorim Eruption (Aegaeum. 17: Liège, 1997\%, 106-8.
}

'J. Dricssen and A. Farnoux, 'Mrcenacans at Malia?', Aegean Archaeology, I (1994). 55 ; J. Driessen and $C$ Macdonald, 'Some military aspects of the Aegean in the late fifieenth and early fourtcenth centuries BC", BSA 79 ( $\left.\mathrm{I}^{8}{ }_{4}\right)$, $49^{-7}$; L. Baumbach, An examination of the personal names in the Knossos tablets as evidence for the social structure of Cirete in the Late Minoan II period', in $O$. Krzyszkowska and L. Nixon (eds), Winoan Society: Proceedings of the Cambridge Ciolloquium 1981 (Bristol, I983), 3-10; J. Driessen. An Early Destruction in the Mrenaean Palace at Knosses (Leuven, iggo). 
phases will be reintroduced. Despite general similarities in the mortuary practices, there are also significant differences relevant to our understanding of the sequence of the innovations that occur, permitting a chronological refinement in our perspective on comparatively swift changes which should not be neglected. These include changes in tomb types (in terms of their relative and absolute frequencies), in the distribution of tomb sites within the valley, and in the use of certain receptacle and artefact types. This article will focus on aspects of the mortuary cridence for LM II, as the first distinct phase of change in the mortuary sphere.

There are only about twenty tombs of secure or probable LM II date known in the Knossos valley. In distribution, they range from the Isopata cemetery in the north down to the Temple Tomb and Gold and Silver Cup Tomb at Gypsadhes in the south. Such evidence advanced for strong mainland influence as is applicable to these burials embraces both tomb architecture and assemblages. Three tomb types appear in the valley for the first time, all of which have been attributed to mainland inspiration..$^{3}$ They are the shaft grave (at the New Hospital Site and possibly Agios Ioannis and Zapher Papoura), the regular chamber tomb with long keyhole dromos (at Agios Ioannis, the New Hospital Site, and the Gold and Silver Cup Tomb), and the tholos (at Kephala). ${ }^{6}$ The assemblages within these tombs, which are generally more wealthy and ostentatious than those of earlier tombs at Knossos, contain specific artefact types that have close associations with contemporary mainland burial customs. These include weapons, vessels, and jewellery in precious metals, as well as ceramic types that are considered to be mainlandderived. 'Tarrior burials', particularly, have been argued to represent mainland customs. ${ }^{8}$ Such burials have been seen to indicate that the individuals here interred had high social status, with the artefacts of precious metals and weaponry (especially swords) compared with similar prestige symbols in the élite warrior ideology witnessed in Mycenae's earlier shaft graves."

The majority of this evidence for mainland influences is persuasive. However, two methodological problems arise in this and the following stage of reasoning. The first, upon which this article will concentrate, is the neglect of those aspects of the mortuary evidence which challenge the idea of a straightforward transferral of mainland mortuary customs to Knossos. The second, related problem, is that these conclusions, seen in the wider context of the other innovations in material culture and practice at Knossos, have occasionally led to speculation over whether we actually have here the burials of intrusive mainlanders comprising or dominating a new élite. ${ }^{\mathrm{I}}$ Indeed, the rather simplistic (and optimistic) equation

\footnotetext{
4 Hagg and Sieurin have also proposed that the introduction of the rooden coflin or bier is a mainland inspiration. As these receptacle types first appear at Poros in LM I B. if not earlier. they may not be strictly relevant to the horizon of LMI II innovations - alternatively: they may indicate that the changes described in the present paper were simply part of a longer process. Sce R. Hagg and F. Sieurin. 'On the origin of the wooden coffin in Late Bronze Age Grecce', BS1 7 ( $(\mathrm{Ig} 82), 177-86$.

$\therefore$ There is no concrete evidence at present that the pit-cave was introduced at Knossos prior to the LMI III A period.

${ }^{6} \mathrm{M}$. Popham and H. and E. Catling. Sellopoulo tombs 3 and 4, two Late Minoan graves near Knossos', BSA 69 (1974), 25j; Rehak and Younger (n. 2), 152; M. Popham, A Late Minoan tomb on Lower Gypsadhes', BSA 75 (I980), I7I. Though, for the challenge to this hypothesis with regard to the chamber tombs, see S. Hood and X. Coldstream, it Late Minoan tomb at Ayios Ioannis near Knossos". BSA 63 (1968), 205: A. Kanta. The Late . Hinoan III Period in Crete: A Surcer of
}

Sites. Pottery and their Distribution Göteborg. 1980/. 297; I. Pini. Beiträge aur minoischen Cräberkunde Wiesbaden, 19681.39 .

- Squat alibastra and krlikes. M. Popham. Late Minoan pottery a summary. BS $162(1967), 3+4$.

${ }^{8}$ Popham and Catling (n. 6), 253 and I. Pini (n. 6). See also O. Dickinson, "Minoans in mainland Greece. Mrenaeans in Crete?" Cietan Studies, 5 (I996), 66 .

9 Macdonald in Driessen and Macdonald (n. 3) $58:$ S. Hood. Another warrior grave at Ayios Ioannis near Knossos: BSt 51 (1956).81.

"' I. Kilian-Dirlmeier, "Noch cinmal zu den 'Kricgergräbern' von Knossos', Jahbuch des Römisch-Germanischen Zentralmuseums Mainz, $32(1985), 196-7$. Macdonald, for example, has suggested that the Zapher Papoura and Scllopoulo cemeteries, cstablished in new locations in L.MI III A. represented an intrusive mainland population, while burials within the existing. Xepalatial cemeteries of Marro Spelio and Gypsadhes were of Cretans. Driessen and Macdonald n. 3:65-6. 
of the use of symbols associated with specific cultural groups with archaeological reconstructions of ethnic identities and geographical origins is largely responsible for that neglect of alternative data which we seek here to redress.

A common premise underlies many of the arguments regarding the distinction between mainlanders and Cretans within the LM II burials, that certain diagnostic elements within the burial record (for example, assemblage composition, tomb architecture, or method of deposition) reflect directly the geographical and biological origin of the individuals being interred, by indicating the specific culture group to which they belonged. " Thus even KilianDirlmeier, by arguing that the LM II-III A warrior burials at Knossos were in fact the continuation of an indigenous phenomenon stretching back to the Early Minoan period, ${ }^{12}$ employs the same interpretative assumptions as those of the migrationists she seeks to refute, but arrives at a different result by citing different evidence. The debate is thereby shifted to the issue of where the earliest examples of the specific cultural traits in question were located, rather than questioning the fundamental theoretical principles of this methodology.

Briefly, the problems with this approach are threefold. First, it is not always possible to establish whether a particular practice is Cretan or mainland in origin. Second, there are burials in which symbols of both Cretan and mainland origin occur together. ${ }^{13}$ Third, and most important, it is simply impossible to prove the biological origin of an individual solely on the basis of cultural attributions in the burial record ${ }^{4}$ - and arguably, therefore, it constitutes a misuse of this evidence to attempt to do so.

There are several implicit and connected assumptions involved in this latter issue that need to be addressed more critically than has been done in the past. One is the equation of archaeologically defined, geographically bounded material culture distribution patterns with ethnic groups. ${ }^{15}$ Second, there is apparently an assumption that such ethnicities will be expressed through mortuary practices. Finally in this context particularly, there is also an apparent unwillingness to consider that indigenous Cretans might voluntarily have adopted such a fundamental cultural practice as mortuary customs from the mainland. Indeed, underlying the preoccupation with proving the physical presence of the mainlanders to whom the Linear B tablets appear to attest, there seems to be an unwillingness to accept that Cretans would voluntarily have adopted mortuary practices and symbolism from what is perceived as an inferior culture: the modern perception of Neopalatial Crete as the cultural pinnacle of Minoan (and, indeed, Aegean) civilization often has as its contrast the perceived relative barbarism of the contemporary mainlanders.

Essentially, each of these assumptions requires critical consideration, whereas until now, I would suggest, they have simply been presumed. Meanwhile, as a result of all these factors, the study of burial customs at LM II Knossos has reached an impasse, only partly alleviated by

\footnotetext{
"Popham in Popham, Catling and Catling (n. 7), 255-6. In the same paper, $\mathrm{H}$. and F. Catling proposed that Zapher Papoura tomb if and Scllopoulo tomb + could only represent mainlanders. This opinion appears to have been modified, however, since $H$. Catling expresses scepticism in a later publication regarding both the presence and political dominance of Mycenacans at Knossos. H. Catling, Some Problems in Aegean Prehiston' C. $1450-1380$ BC: (Oxford, 1989), 6-7, 20.

"2 Kilian-Dirlmeier (11, 10), 208-9, $21 \mathrm{I}$.

I:3 Dickinson notes the occurrence of mortuary symbolism
}

of mainland and Cretan origin in the same burials, though for the example of the chest lamax as a Minoan artefact, it should be noted that this was only reintroduced at Knossos in LMI III A. Dickinson (n. 8), 66.

1. Pace Macdonald (n. 3), 65

15 S. Shennan, 'Introduction: archacological approaches to cultural identity', in S. Shennan (ed.), Archaeological tpproaches to Cultural Identity (London, 1989), 5 6; S. Jones. The Archaeology of Ethnicity: Constructing Identities in the Past and Present (London, 1997). 
Kilian-Dirlmeier's redirection of interpretation towards issues of rank and gender differentiations and intra-cemetery spatial organization.

\section{Perceptions of Mortlary Practices}

One way out of this impasse would be to recognize and explore the potential flexibility of supposedly bounded cultural practices, and to reassess the data in the light of evidence for mortuary practices as a versatile arena of social negotiation. It is worth emphasizing this aspect of the social role of mortuary practices -one that has proved central to our understanding of social and political dynamics on the Greek mainland in the Late Bronze Age, but has not received much attention in the context of Knossos. It has been cogently argued for many archaeological contexts, within and beyond the Aegean, that the burial record is a prime forum for the negotiation of social roles and power relations. ${ }^{16}$ The rituals preceding, during, and following the actual interment of the deceased thus provide an ideal context for advertisement by the living to the living, whether on the level of the individual, the kin-group, or the community. ${ }^{17}$ Burial should, therefore, be considered as one of the many possible public fora in which social relations and identities are asserted, reinforced, challenged, and renegotiated. On the Greek mainland specifically, the ideological manipulation of the burial ritual and tomb assemblage, architecture, and location, has been explored as a dynamic agent in a context of political competition and status consolidation. ${ }^{18}$ As Voutsaki observes, "the crucial factor is ideology, the way people . . . choose to represent themselves', ${ }^{19}$ so that burial should not be interpreted as simply a passive reflection of a static social 'reality'. Rather, it can be a powerful resource in the hands of various social groups with different priorities and ideologies, capable of acting back on society and expressing various perceived or desired 'realities'. ${ }^{20}$

Because of this, it is hazardous for the archaeologist to assume either that burial practices were conservative (and therefore diagnostic of any particular culture group), or that the meaning of the burial record is straightforward to interpret. Burials were not carried out with the interests of the archaeologist in mind, but as a means of communication between the living. Recognized as such, the burial rccord becomes a much less reliable archaeological resource for establishing the personal histories of the dead, as opposed to the projected identities conceived by the living who buried them.

\section{ANALYSIS OF THE LM II DATA}

Having made the above theoretical points, let us now turn to look at the LM II data themselves, where several different practices can be observed. Onc group that can be

\footnotetext{
It) M. Parker Pearson, "The powerful dead: archacological relationships between the living and the dead', C:17 3:2 (1993), 203-29; M. Shanks and C. Tilley; Ideology; symbolic power and ritual communication: a reinterpretation of Ncolithic mortuary practices', in I. Hodder (ed.), Symbolic and Structural Archaeologr (Cambridge, 1982), I29-54.

"J. Thomas. Rethinking the Veolithic (Cambridge, I991). I04-5; M. Parker Pearson. 'Mortuary practices, society and ideology: an ethnoarchacological study', in Hodder (n. 16). II 2 .

18. e. S. Voutsaki, Social and political processes in the
}

\footnotetext{
Mrcenaean Argolid: the evidence from the mortuary practices: in R. Iaffineur (ed.). Politeia: Societ? and State in the Aegean Bronse Age Acgaeum, 12: Liège, 1995) 55 66: J. C. Wright. "Death and power at Mycenae: changing symbols in mortuary practice: in R. Iaftineur (ed.). Thanalos: Les

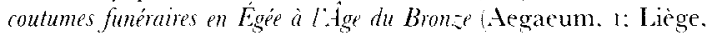
$1987, I_{7}{ }^{-1}-8_{4}$.

I" Voutsaki (11. 18) 57. C.f. I. Hodder, Simbols in Action: Ethoarchaeological Studies of Material Culure (Cambridge. I982: 201.

*11 Voutsaki (n. 18\% 57: Parker Pearson (1. 16.
} 
distinguished consists of the Acropolis Tomb, the Agios Ioannis Gold Cup Tomb, the New Hospital Site tombs I, II, III, and V, and the Silver and Gold Cup Tomb at Gypsadhes. These burials, which include all the LAI II warrior burials, are, as has often been argued previously, quitc clearly 'Mycenaeanizing'. Differences from mainland practices can be noted-for example, shaft graves at Knossos, although internally homogeneous, display interesting differences from their mainland parallels - structurally and with regard to interment numbers that would repay closer consideration. ${ }^{21}$ The same applies to the new chamber tomb type at Knossos, which was deliberately and consistently designed to hold only a few interments (two at most in LAI II), rather than the multiple burials often found in the comparable tomb type on the mainland. ${ }^{22}$ However, in general, the artefact types accompanying these burials (which are very homogeneous) are indeed similar to those found on the contemporary mainland, and so it would not be unreasonable to argue that a mainland-oriented identity was being expressed in death for the individuals involved. That these are not grounds for presuming the geographical origins of the people so interred, however, is suggested by the data from the other tombs in the valley.

Unfortunately; little can be said regarding the LM II use of the Marro Spelio cemetery (tombs 7 and 9), since the assemblages and interments accompanying the few diagnostic ceramics found in these reused Neopalatial chamber tombs cannot be reconstructed. The burials in the Temple Tomb, meanwhile, associated with an LM II-III A I assemblage, are anomalous, rendering them difficult to explain as anything other than exceptional and historically contingent. However, more constructive data can be derived from the group of tombs from the northern end of the valley that have received surprisingly little attention in the past. They are the monumental tombs of Isopata and Kephala-specifically, the so-called 'Isopata Royal Tomb',"3 tombs I, II, and V of the Isopata cemetery,', and the tholos tomb at Kephala. ${ }^{25}$

These five tombs are among the largest known mortuary structures constructed in the Knossos valley during the entire Late Minoan period, with the largest - the Isopata Royal Tomb-having a main chamber area of $50 \mathrm{~m}^{2} .^{26}$ They appear rather suddenly in a brief

\footnotetext{
${ }^{2} \mathrm{O}$. Dickinson. 'Cist graves and chamber tombs". BSt 78 1983 - 56: Wl: Cavanagh and C. Mee. A Priate Place: Death in Prehistonic Greece (SIMA 125: Jonsered. 1998: 43 4. Cavanagh and Mee note that wo of the shaft graves in Grave Circle 1 had rock-cut ledges. though these ledges supported wooden beams, as opposed to the stone slabs found at knossos.

2: Macdonald in Driessen and Macdonald n. 3. $65: 0$. Dickinson, The Aegean Bronte Age Cambridge. I994. 230: Dickinson (11. 21 6.65 . However. it should be noted that the numbers buried in the carly chamber tombs are greater in Iessenia than in the Argolid $(O$. Dickinson. pers. comm.

2. A. Evans. The prehistoric tombs of Knossos. Archaeologia. 59 1905) $526-62$. In this publication $(\mathrm{p} .560$, he proposed a MII III date for the construction of this tomb. on the basis of presumed architectural parallels in Egypt, the mason's marks and the monumentality of the structure. However, he later revised this to LAI II. a date in line with the earliest of the ceramics found within it (Erans, Pl/ iv: $7 / 4$ ).

${ }^{2}$ A. Exans. "The Tomb of the Double Axes and associated group". Archaeologia $65(1914)$ 1-59. Isopata $V$ is the only tomb of these three whose date of use is uncertain. In the
}

original publication, Evans argued for a LMI I date on the basis of the ritual ressels in the assemblage pointing to parallels from a I.M I context at Agia Triadha p. 27! but orcrlooking the occurrence of a vessel of similar form in the L.M II lsopata tomb II in the same cemetery: However. Evans appears to have changed his opinion subsequently. assigning a date of LAI II in PM iv, 88I. This dating is supported by the squat alabastron and high-beaked jug in the same assemblage.

$\Rightarrow$ R. W. Hutchinson, it tholos tomb on the Kephala: BSA $\left.{ }^{\mathbf{I}}: \mathbf{I} 956\right), 74-80$. Alehough the excavator preferred a LMI I date for the original use of this tomb. I shall follow Popham's dating of LMI II. on the basis of the Palace Style jar fragments, and the location of a Neopalatial structure in the vicinity; from which the earlier material could have been introduced. See M. Popham. 'Review of R. II. Hutchinson's Prehistoric Crete. fHSS 86 i1964), 209-10.

21) The areas of the main chambers of the other tombs are as follows: Isopata tomb II. roughly to $\mathrm{m}^{2}$ : Isopata tomb IV $28 \mathrm{~m}^{2}$ : the Kephala tholos $24 \mathrm{~m}^{2}$ : Isopata tomb I. at $10 \mathrm{~m}^{2}$. is the smallest. 


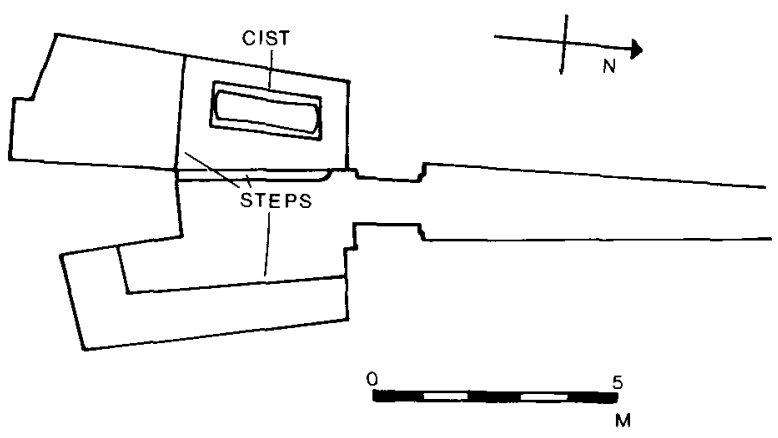

FIG. I. Plan and section of Isopata Tomb II (after A. Evans, 'The Tomb of the Double Axes and associated group". Archaeologia, $65(\mathrm{Ig}) \mathrm{4}), \mathrm{pl} . \mathrm{v})$.

building horizon in the LM II period, and none have any close architectural predecessors in the valley. ${ }^{27}$ Considering their originality in this sense, as well as their impressive sizes, and the indications of wealthy assemblages found even in those that had been plundered, one might question why these five tombs have received so little attention in the past, in comparison with the contemporary burials to the south and west. I suspect that the reason for this is that their assemblages and architectural designs do not corroborate the mainland invasion hypothesis to the same extent as do the assemblages belonging to those burials more popularly cited. Indeed, the inspirations for these tombs are not only distinctly heterogeneous, and diverse in their cultural and contextual origins, but they are combined here in such innovative ways that the overriding impression they convey is of experimentation with mortuary symbolism.

The chamber tomb Isopata II (or 'Tomb of the Double Axes') appears to utilize traditional mortuary ideas, in combination with religious and palatial symbolism new to this context, most of which is apparently indigenous in its inspiration. On the one hand, the plan of the double chamber, divided by a central buttress facing the entrance, is reminiscent of the irregular arrangement of the multiple chambers of the Neopalatial tombs at Marro Spelio, in the same valley, which are usually cited as examples of specifically Cretan tomb architecture (FIG. I). ${ }^{28}$ The half-engaged column carved into the face of the buttress, however, is unique. Evans considered it reminiscent of an iconographic motif found in other media, such as ceramic and stone vessels or frescoes, where it seems to have bcen used to represent palatial architecture. ${ }^{29}$ Other examples can be found in seal iconography, $3^{30}$ and in the later sculpture surmounting the Lion Gate at Mycenae. ${ }^{31}$ Simultaneously, the buttress itself may have deliberately recalled the central feature of the pillar crypt, an architectural type in high-status

\footnotetext{
$\because$ While the Temple Tomb has been cited as a Neopalatial burial place, it is not architecturally related to any of these five tombs. It should also be noted that there is no direct cridence that this building was actually constructed for such a purpose, although its location beyond the settlement limit and spatial association with Neopalatial chamber tombs suggests that it may have had mortuary connections at this timc. Erans, P.I is, 973; J. Soles. The Prepalatial Cemeteries at Mochlos and Gournia and the House Tombs of Bronze Age Crete Hesp. Supplement 24; Princeton, 1992), $5_{5}^{1-5}$

2: Compare the architecture of the Middle Minoan
}

multiple chamber tombs at Marro Spelio. E. J. Forsdyke. "The Marro Spelio cemetery at Knossos". BSA 28 (1927) $2+3-96$.

29 Evans (n. 24) 36. Evans also notes. however, that such representations usually depict a column which tapers towards the base, whereas this carving has parallel sides.

3" J. Younger, The Lonography' of Late Minoun and Wycenaean Sealstones and Finger Rings (Bristol, 1988i, 278-0.

${ }_{31}$ See G. Mylonas. Mrenae and the Mrenaean ige (Princeton, 1966). 173-5 for a similar interpretation of the column depicted on the Lion Gate. 
Neopalatial buildings, whose function is supposed to have been cultic. ${ }^{2}$ This suggestion is supported by the presence of other Cretan religious symbolism: cult paraphernalia in the assemblage (a bull's head rhyton, a ring-handled vessel similar to those in Isopata tomb $\mathrm{V}$ [see below], and three bronze double axes), and in the carving of the burial cist itself in the shape of a double axe. Although Neopalatial Cretan examples can be cited of large-scale expenditure on ritual activities at the mortuary locale, in association with permanent architectural facilities, 33 the explicit accommodation of cultic symbolism within a tomb (as opposed to a mortuary shrine) is entirely innovative. ${ }^{3+}$ Finally, it should also be noted by contrast with the aforementioned indigenous symbolism, that the assemblage here also contains artefacts that have been associated with mainland burial customs, such as the squat alabastron, the metal vessel, and the weaponry (arrowheads, knives, and a possible sword). ${ }^{35}$

The source of inspiration for the mortuary architecture of the two corbel-vaulted tombs at Isopata is still very much open to debate (FIG. 2). Following the discovery of the high status tombs at Late Bronze Age Lgarit, Evans and Schaeffer were convinced that there was an architectural link between them..$^{36}$ Indeed, they share striking parallels in the roof structures, rectangular chambers, and central niches in the back walls of the chambers (FIG. 3). However, a hypothesis that these Levantine tombs were imitated at Isopata is slightly problematic, since the most monumental of the tombs at Ugarit, which are most closely akin to those at Isopata in terms of size and quality of masonry, have been dated to at least half a century later.37 Indeed, this caused Schaeffer to postulate that the influence was rather in the opposite direction..$^{3^{3}}$ However, this hypothesis is also difficult, since the general tomb type at Ugarit (rectangular subterranean chamber with dromos) had an indigenous ancestry dating back to the eighteenth century BC. This problem of the extent of Levantine influence at Isopata, therefore, remains unsolved for the moment. 39 If we turn to the mainland, we find that Tomb Rho in Mycenae's Grave Circle B also provides an interesting parallel, despite the lack of a dromos or niches in this tomb. $t^{\circ} \mathrm{A}$ comparison with the mainland tholoi also has some merit, especially with respect to the corbel-vaulting and the presence of long dromoi and burial pits in the main chambers (the latter two features not paralleled at Ugarit). Nevertheless, there is the alteration of the fundamental feature of the chamber shape and the use of niches. A further, but entirely innovative feature in the Isopata tombs is the forchamber, that within the Royal Tomb also having side niches (the contemporary Kephala tholos provides the only known parallel). It should also be noted that mason's marks appear on some of the ashlar blocks within both tombs, though it is

\footnotetext{
32 Ibid.; G. Gesell. Toun. Palace. and House Ciult in .Minoan Crete SIMA 67: Götchorg. 1985;. 26 9: X. Marinatos. Minoan Religion: Ritual, Image and Simbol Columbia. 1993), 93-4.

is For cxample, the built tomb at Myrtos Pyrgos. Building Four at Archanes Phourni. 'Iomb 5 at Agia Triadha and the Temple Tomb at Knossos. Soles (n. 27), 120 5. I39 42, 1 $76-9$. For the Temple Tomb. sec references in n. 27 .

it See n. 27. for a contrast with the Temple Tomb.

is W. Cavanagh. Inmovation, conservatism and variation in Mycenacan funcrary ritual, in $\mathrm{K}$. Branigan (ed.), Cemetery and Societ) in the Aegean Bronze Age (Shefficld, 1998), 106; Cavanagh and Mee (n. 21). 50-I.

$3^{6}$ C. Schacffer, L Garitica I: Études relatives aur découcertes de Ras Shamra Paris, I939).
}

\footnotetext{
3. In fact, they are usually dated to the late I 4 th- 33 cent. BC: J.-F. Salles, Rituel mortuaire et rituel social à Ras Shamra/Ougarit, in S. Campbell and A. Green (eds), The Archaeologl of Death in the Ancient lear East (Oxford, 1995), 173.

$3^{37}$ Schaeffer (n. 36), 92.

34. It should also be noted that the Lgaritic tombs were invariably intramural, in direct contrast to those at Isopata, and that ther had much shorter dromoi.

"This corbel-raulted tomb, dated to I.H II A or LH II B, has been compared with the Lgaritic tombs. G. Mylonas, $O$

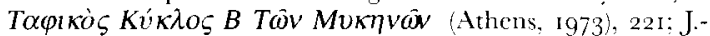
C. Courtois, 'Ras Shamra', in L. Pirot et al. (eds), Supplément au Dictionnaire de la Bible (Paris, 1979), 1200-1.
} 


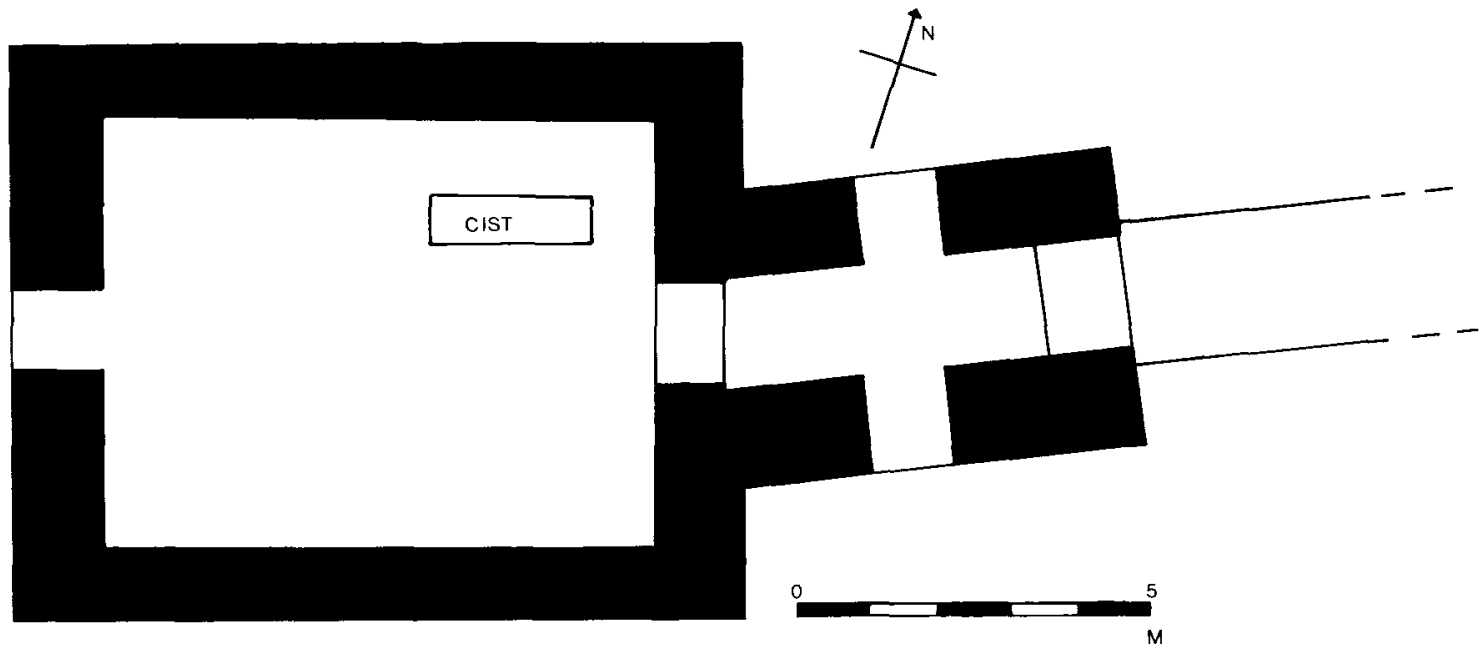

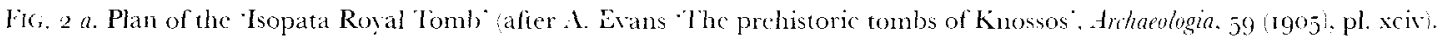

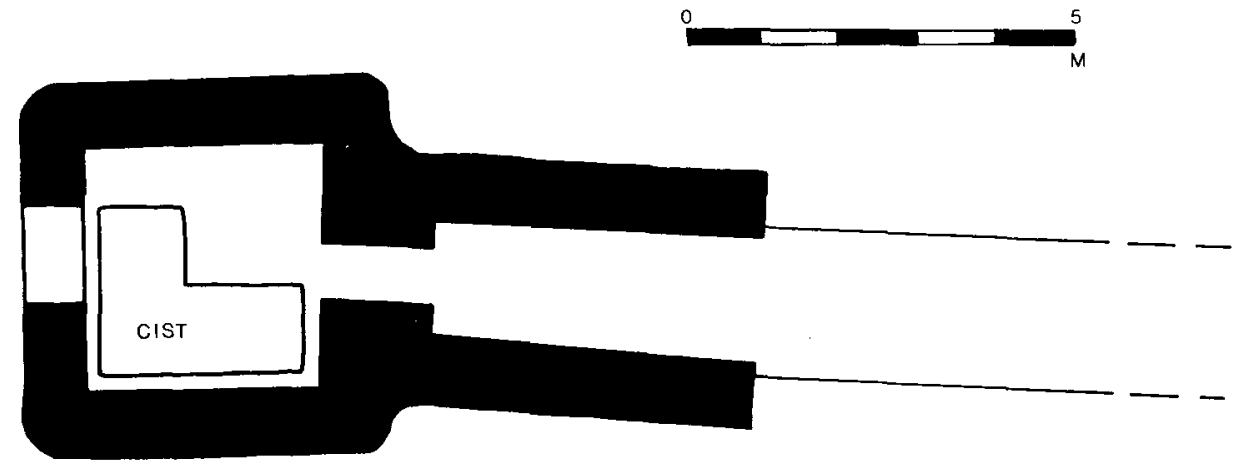

Fic. 2 b. Plan and chamber section of Isopata lomb I after . I. Evans, "The Tomb of the Double Axes and associated group". Archarologia. $6_{5}$ 191 + fig. 10 .

uncertain whether such marks were an important visual symbol in the tomb, or else simply a functional aspect of the production process of the masonry. ${ }^{1}$ This architectural feature appears to be Gretan in origin, though its appearance in the mortuary context is certainly unusual. ${ }^{+2}$ In terms of their assemblages, the artefacts in Isopata I are generally unhelpful in terms of establishing cultural origins, though the Isopata Royal Tomb was interesting in that

"That in Isopara tomb I was on a stone found in the burial pit of the main chamber. Those in the lsopata Royal Tomb were more prominent, on the walls of the main chamber and forehall. as well as in the burial pit. One block, remarked upon by Eans because it had a series of four mason's marks on onc face, may have formed the coping stonc of the niches at the back of the main chamber. Evans $(11.23 \cdot 55 \%$.
1: S. Hood. 'Cretans in Laconia?", in J. M. Sanders ed.;

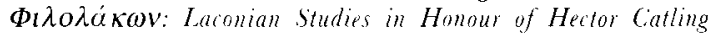
London. 1992\%, 137. One mainland parallel can be found in the LH I II Peristeria tholos, where two mason's marks were carved into one of the door jambs at the entrance to the chamber: $A R 1959$ 60. I3. 
Fig. 3. Plan and sections of Tombe I at Lgarit (after C. Schacfler. L garitica I: Eludes relatioes aux deconcertes de Ras Shamra (Paris, 1939) fig. 80).
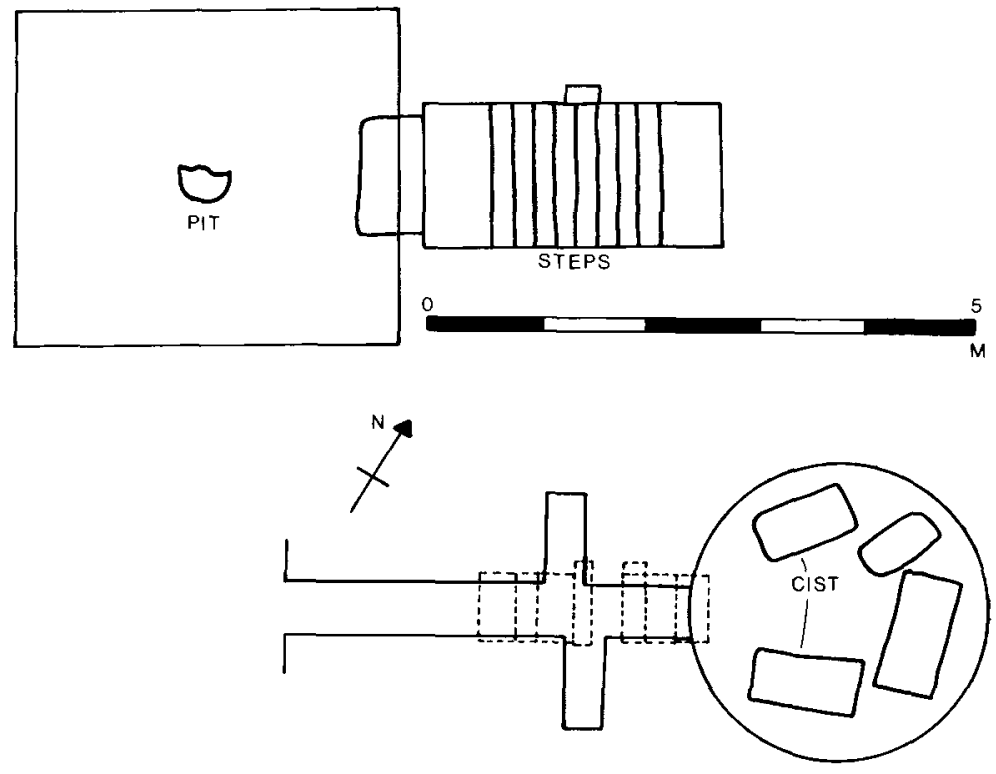

Fic. 4. Plan and section of the Kephala tholos tomb after R. W. Hutchinson. A tholos tomb on the Kephala:, BSA $\left.5^{1}(1956), 75\right)$

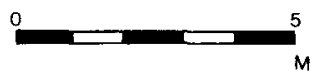

it contained many stone vessels, apparently from the earliest burials in this tomb, some of which Evans described as being Egyptian in origin. ${ }^{43}$

When we turn to the Kephala tholos, the architectural plan appears to be more straightforward, as the basic idea of the built tholos tomb with burial cists in the main chamber was surely borrowed from the mainland (FIG. 4). However, the covered forehall with side niches, like those of the Isopata Royal Tomb, is not paralleled on the mainland. Again, as in the Isopata tombs, mason's marks appear in this structure, though here including a brief Linear A inscription at the entrance to the main chamber. ${ }^{++}$Unfortunately, it is impossible to reconstruct the original assemblage, or assemblages, of this tomb, apart from the fragments of Palace Style jars, owing to its extensive reuse and disturbance.

Finally, Isopata V (otherwise known as the 'Tomb of the Polychrome Vases') is the only example of the group whose architectural affinities are straightforward to reconstruct, being a regular chamber tomb of the type usually attributed to mainland influence (FIG. 5). Its inclusion within this group is based upon its monumentality and its assemblage, which comprises artefacts of both mainland and Cretan inspiration. On the one hand, there are two squat alabastra, a vessel type that appears to have been introduced to Knossos from the mainland at about this time, and which appears frequently in the better known LM II burial contexts in the valley.5 In contrast, there are

\footnotetext{
ti Exans (n. 23): 55 -6. Warren supports this identification.

P. Warren. Winoan Stone Vases (Cambridge, 1969 ), $10_{5}$.

+t See n. 42 .

t. Squat alabastra are found in the Acropolis tomb. Tombs
}

I, II, III, and $V^{\prime}$ at the New Hospital Site, and the Gold Cup Tomb at Gypsadhes. Sce S. Hood and D. Smyth, Archaeological Survey of the Knossos Area. (London, 1981), nos. $7 \mathrm{I}$, I $49 \cdot 3^{2} 4$ 


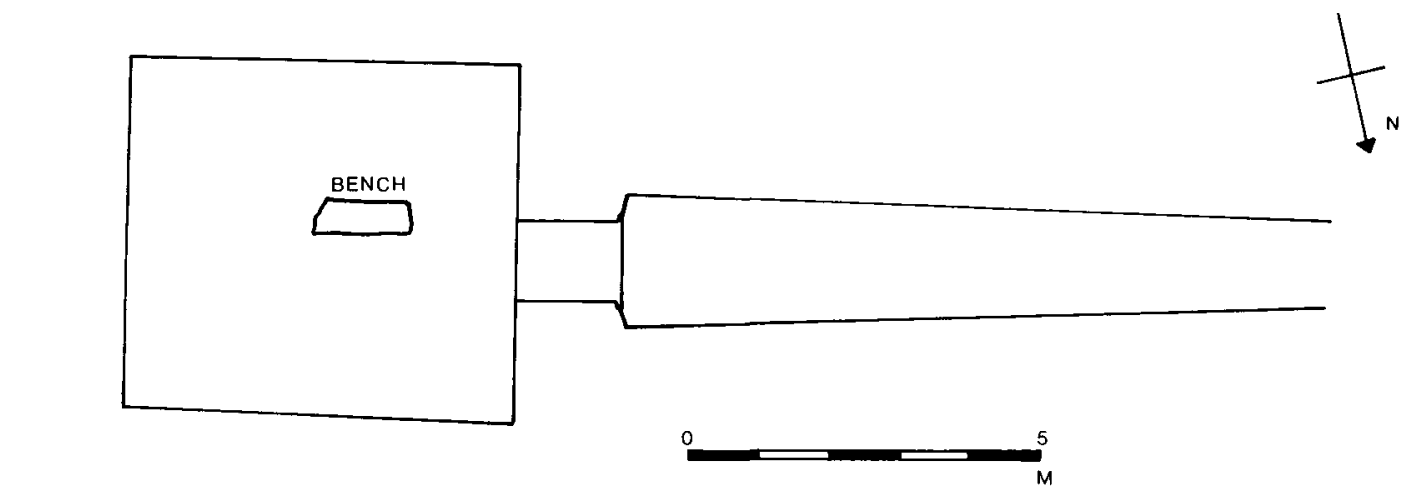

FIc. 5. Plan of Isopata Tomb V after A. Evans, "The Tomb of the Double Axes and associated group'. Archaeologia, 65 (19r.4). fig. 33 c).

also four polychrome ring-handled vessels, after which the tomb was named by the excavator and which appear to be entirely indigenous. ${ }^{6}$ Their closest parallel in a mortuary context is in Isopata tomb II, and their function may have been cultic. This tomb is not experimenting with symbolism to the same extent as the others in this group, it provides an interesting link with the more explicitly 'Mycenaeanizing' tombs mentioned earlier. It might indicate that the relationship between the two groups was less a dichotomy than one of different positions on a continuum from overt Mycenaeanization to a more selective adaptation of mainland ideas.

\section{DISCLSSION}

Overall, these five tombs clearly suggest that certain individuals in the Knossos region were experimenting with the use and combination of different types of symbolism in the mortuary context, not only of divergent geographical and cultural origins, but also from contexts other than the specifically mortuary. In the climate of extensive interregional interactions in the Aegean and the Near East in the Late Bronze Age, in which Crete, and especially Knossos, was closely involved at this time, such experimentation with external cultural symbolism should come as no surprise. ${ }^{+7}$ Thus, the main point of interest with regard to these tombs clearly moves beyond simply establishing the cultural identities of the individuals involved. Not only is mainland mortuary symbolism being adapted here (as opposed to simply adopted), but indigenous cultural practices from other contexts are also deliberately transferred into the burial context, in combination with architectural innovations that cannot be paralleled at all.

In the context of the range of other innovations in Knossian material culture in LM II, these tombs should be viewed as part of the social, and probably political, upheaval taking place at this time. Within this context, it appears that a certain number of individuals had chosen mortuary ostentation as a means of establishing, or sustaining, a particular status, adapting methods which had proved successful elsewhere, as well as indigenous ideas not

t7 For references to this extensive subject, see Rehak and 
previously deployed in such a way. First, the monumentality of these tombs and the wealth inferred from their assemblages indicate that significant expenditure had been devoted to these burials. Second, the vaults of the tholos and the two corbel-vaulted tombs would have protruded above ground level (presumably covered by a mound); considering the positioning of the Kephala tholos and Isopata Royal Tomb near ridge summits, it would be interesting to speculate as to whether they were deliberately sited to be conspicuous in the landscape. Unfortunately, it is not clear whether a main road between Knossos and the harbour town to the north passed by the Kephala and Isopata sites, although Hogarth mentions the existence of a north-south road in the vicinity of the Kephala tomb. ${ }^{8}$ The distribution of the three tomb sites concerned along a north-south axis up the valley between the palace and the harbour town may indicate the presence of such a route (though even if it was actually located further to the east, the most prominent tombs may still have been visible).

The third, and most interesting, indication that status advertisement was a significant factor in the construction of these tombs is the deliberate borrowing of specific symbols that already had existing high status associations in their original contexts. It is widely accepted that tholoi on the mainland were employed within political competition on both community and regional levels ${ }^{49}$ - and indeed the basic idea of using monumental tombs here, of whatever design, for such a purpose probably had the same origin. The incorporation of indigenous cultic symbolism within such a framework, as in Isopata II, can also be interpreted in this way, given the apparent extension in the Neopalatial period of palatial control over certain religious practices, as a means of power legitimation through purely ideological means..$^{\circ}$ Finally, we have evidence in three of our five tombs (indeed, all those which were constructed with masonry, rather than simply hollowed from the ground) for the use of ashlar masonry, a material previously, and otherwise, associated with high status architecture. Hood makes the valid point that these blocks of ashlar masonry could have been appropriated for use here and at the Isopata Royal Tomb from earlier, non-mortuary structures. ${ }^{{ }^{I}}$ This would not affect the present hypothesis, since the issue at stake is not the source from which these particular ashlar blocks came, but the reasons for their deployment in this context. The very appropriation (whether literally or metaphorically) of ashlar masonry as a building material in these tombs suggests a desire to emulate in death what was probably one of the key mechanisms for expressing and reinforcing élite status and authority in the Neopalatial period: the construction of monumental buildings in ashlar masonry in the settlement context. Indeed, if the masonry for these tombs was reused, it would be interesting to consider whether it was not only the material that was being appropriated, but also the ideological associations of the structures it originally comprised.

Thus ostentation, and an innovative requisitioning of high status symbolism from other contexts, are the factors that unite these tombs, and it would not be unreasonable to suggest that such symbols were deliberately selected to be deployed here in a similar way, for purposes of social legitimation. However, we should not forget the architectural diversity also apparent among them. The four most innovative of these tombs comprise one tholos, two corbel-

\footnotetext{
${ }^{* 3}$ Hutchinson (n. 25).74.

19. e.g. S. Voutsaki. 'Mortuary evidence. symbolic meanings and social change: a comparison between Messenia and the Argolid in the Mycenaean Period, in Brangan (n. 35) $4^{1} 58$.

"e.g. A. Peatfield. Palace and peaks: the political and
}

religious relationship between palaces and peak sanctuaries', in R. Hägg and N. Marinatos. The Function of the Minoan Palaces (Stockholm, 1987), 89 93: Rehak and Younger (n. 2). $I_{4} \mathrm{I}$ 2. For other references, see Dickinson $($ n. 22), 27+ j.

${ }^{i} \operatorname{Hood}(\mathrm{n} .42)$, I37. 
vaulted tombs, and an irregular chamber tomb. The types and combinations of different symbols borrowed, and the nature of their arrangement in the burial context, vary from tomb to tomb, with only two sharing the same basic architectural plans. In other words, although the basic idea of utilizing symbols from various contexts for social advertisement is consistent throughout these tombs, the results are widely divergent. The overall impression created is of a segment (or segments) of the community with a common purpose, and an idea that mortuary ostentation might be a key to their success, but without any agreement as to how this tool should most effectively be utilized in this new social situation.

Several scenarios could be advanced regarding the interrelationship between these tombs, and their situation within the wider community. The clustering of three of the tombs in the Isopata cemetery suggests that they at least represented a distinct social group. However, it may be that those responsible for the construction of all of these tombs were only connected to each other within a broad category, on the basis of their aims, rather than their backgrounds or usual social affiliations. Two alternatives regarding the motivation for the construction of the tombs will be considered here, either or both of which could be applicable, according to one's views regarding the above issue of internal cohesion. On the one hand, these tombs could be seen to represent the LM II élite at Knossos, who, whether native or intrusive in terms of their personal origins, were experimenting with a medium novel at Knossos, to secure their position within a still unstable political environment. The siting of the tombs at Isopata, which have intervisibility with the coast and harbour town, rather than with the valley to the south, may have been a tactic for advertisement not to the local population, but principally to the outside world. On the other hand, one could equally argue that these tombs represent a social group not already established within the traditional, Neopalatial local ruling élite at Knossos, but who had precipitated, or simply taken advantage of, an opportunity to contend for greater power in this sphere. Since none of the tombs are intervisible with the palace, but instead congregate to the north of the valley, they may equally represent a symbolic territorial encroachment upon the domain of the Knossian élite by outsiders more closely associated with the harbour area. The very decision to employ such a novel mechanism as monumental mortuary architecture for social advertisement may have resulted from exclusion from access to the methods traditionally employed at Knossos, rather than a conscious rejection of such ideas in favour of new strategies. At any rate, it needs to be stressed that the fact that these are the most impressive tombs in the valley in this period does not necessarily indicate that they represent the highestranking individuals at Knossos, as opposed to those who were simply making the most effort through this particular, archaeologically prominent, means of status negotiation. We should avoid the pitfall of assuming that the elements of past activities that are most conspicuous in the archaeological record were also the most prominent, and successful, at the time.

One could speculate as to why, although the Kephala tholos and Isopata Royal Tomb continued to be used for burial purposes beyond LM II, and the Isopata cemetery expanded in LM III A, there is no known evidence for the construction of mortuary architecture in the valley on the scale of the most monumental of these tombs ever again. It may be that these tombs were successful, precluding the need for further expenditure in this direction on such a scale. Conversely, all innovations can be seen as risk-taking strategies, ${ }^{52}$ and it is possible that these particular experiments simply did not prove as viable as had been hoped.

3t R. Forrence and S. van der Leeuw; 'Introduction: what s new about innovation?", in R. Torrence and S. van der
Leeuw (eds). What's leae' A Closer Look at the Process of Innozation (London. I989). I0.12. 


\section{CONCLLSIONS}

This article has suggested that mortuary symbolism was being used in more than one way in a small number of tombs at LMI II Knossos, in a social or political context that was conducive to competition. While the traditional argument that some of the burials were vehicles for the expression of mainland ethnic identities has not been denied as one possible scenario, the problems with constructing geographical origins from the burial evidence have been highlighted, and an alternative approach suggested that focuses less on who these people were (in the biological sense), and more on the immediately relevant issue of how they chose to present themselves (in the social and political sense). This involves a step beyond normative assumptions regarding cultural practices, to recognize the potential ideological power of the burial ritual, especially in times of crisis. The validity of such an approach was highlighted by comparison with the evidence from the tombs at Isopata and Kephala, where overt experimentation with mortuary ideas, through the fairly opportunistic manipulation of high status symbolism in the burial context, is more apparent. Although the two groups could be seen as diametrically opposed, it is interesting to consider them rather as variations within a more general strategy of manipulating symbols from different cultural contexts in a time of social flux.

In this light, it is interesting to note that there was similarly active experimentation in the mortuary sphere on the mainland in the LH I and II periods, especially in the diversification of tomb types, including shaft graves, tholoi, chamber tombs, and even the unusual Tomb Rho at Mycenae.53 This parallel might indicate that part of the process of 'Mycenaeanization' at Knossos was actually mortuary experimentation. It also suggests that the manipulation of the mortuary context as a response (and contributor) to social changes was in fact a wider Aegean phenomenon at this time. Thus the dynamics seen at LM II Knossos, while locally specific in many ways, also need to be integrated into a wider horizon of social and political transformation. 